\title{
COMENTÁRIOS SOBRE ESTUDO DE IMPACTO NO SISTEMA DE AVALIAÇÃO DO RENDIMENTO ESCOLAR (VERSÃo CONDENSADA)
}

Meu primeiro comentário é para felicitar o esforço đesenvolvido para levar adiante uma avaliação das inovações promovidas pela Secretaria de Educação do Estado de São Paulo. Sendo a escola uma instituição que constantemente avalia seus alunos, o sitema escolar é muito poucas vezes avaliado e as inovações educacionais não estão alheias a esta situação. A avaliação que a escola faz é privada - é dos alunos, dos pais, dos professores -, e só a conhecem os personagens diretamente envolvidos. No entanto, a avaliação das inovações do sistema escolar é um tema publico e é influenciado pela opinião dos demais.

Um segundo aspecto que me parece importante destacar é o carater externo que tem a avaliação que hoje discutimos, que oferece um maior grau de credibilidade e independência àqueles que tomam as decisões.

O tipo de estudo mostra antecedentes muito importantes no campo de investigação educacional - creio que não se trata apenas de uma avaliação do impacto - , mas que, sem dúvida, servirão de insumo para aqueles que tomam decisões de politica educacional e também para os atores diretamente envolvidos no processo de aprendizagem dos meninos e meninas.

Neste sentido, Abello (1987) afirma que "a avaliação não se limita à determinação dos resultados finais de um programa que, indubitavelmente, formam a parte principal do mesmo". A avaliação é uma investigação

* Coordenadora Nacional do Programa 900 Escolas - Ministério da Educacão do Chile. 
explicativa. Briones (1985) estabeleceu claramente a conotação investigadora da avaliação, pois proporciona critérios fundamentados cientificamente para tomada de decisões em relação à estrutura, funcionamento e desenvolvimento do programa.

Encontramos antecedentes muito relevantes no documento para avançar em políticas educacionais que tendem a assegurar uma escola de qualidade, que torne universal não só a permanência, como também o acesso a ferramentas culturais básicas que possibilitem o desenvolvimento de novos saberes.

Desenvolverei meus comentários a partir de minha experiência como usúaria das avaliações e como implementadora de políticas de melhoria da qualidade. Parece-me importante destacar esse ponto, pois algumas questões que me faço devem-se a que o documento não oferece todos os antecedentes que se requerem para entrar em profundidade em cada um dos temas. Por isso peço desculpas se algumas das perguntas que faço já têm resposta por parte dos que participaram nas investigações.

$\mathrm{O}$ documento suscita três perguntas fundamentais em seu início que a avaliação deve responder. Então sobre elas organizei meus comentários.

\section{I - HÁ MELHORIA DAS APRENDIZAGENS?}

As cifras mostram aumentos mas surgem algumas interrogações para que a resposta se complete:

1 - Parece-me importante esclarecer quais são as condições de entrada no Programa de Escolas-Padrão, como são selecionados os $10 \%$ de escolas da Região Metropolitana. Para incorporar uma escola, quais os fatores de organização, tipo de população atendida, quantidade de professores, tipo de qualificação, etc., foram considerados. Isto para determinar como estes critérios (variáveis consideradas ao ingressar) influem na melhoria e o impacto que mostra a avaliação.

2-Em termos de análise dos dados seria conveniente uma análise por grupos de escolas. Entendo que se homogeneizaram por determinação geográfica, tamanho, índice de evasão, repetência, etc. Se as escolas dos quatro estratos têm variáveis similares, podemos estabelecer grupos dentro de cada estrato para responder perguntas como: que tipo de escola dentro de cada estrato tem maior rendimento? Quais são as escolas que se benefeciam menos com a inovação. Parece-me importante estabelecer quais são as características e as diferenças dentro desses grupos. Ou, se as escolas são todas iguais, creio que seria importante colocar no documento.

3 - Ao considerar a melhoria dos rendimentos escolares e os fatores associados às escolas e famílias, faz-se necessário considerar o que Bosker chamou "efeito escola", isto é, consistência e estabilidade da escola na melhoria. 
Neste estudo poder-se-ia analisar a consistência através da correlação de resultados entre os rendimentos de Matemática e Português. A estabilidade se refere a análises de resultados ano a ano em cada uma das escolas.

Está claro nos resultados o maior impacto da inovação no primeiro ano de participação das escolas. Mas é necessário conhecer o ritmo de crescimento das escolas no tempo. Quantas se mantêm em seu aumento? E quantas têm um único aumento e nas medições posteriores voltam ao seu nível inicial? O que acontece com as escolas em termos de estabilidade de melhoria, ou em que ponto de melhoria a escola se estabelece?

4-A estabilidade também está associada aos níveis de aproprição da proposta; quanto a inovação é produto do agente externo que promove a inovação, e quanto é produto recriado pela escola e incorporado às práticas pedagógicas habituais.

Através da literatura conhecemos três tipos de apropriação:

A) Apropriação Reprodutiva: a proposta se mantém tal como foi desenhada sem sofrer maiores modificações. Estas inovações se mantêm com a presença de um agente externo, e, em geral, tendem a desaparecer quando há a saída deste.

B) Uma segunda apropriação é a Seletiva: é quando são introduzidas certas mudanças sem que haja variações substanciais da proposta.

C) O terceiro tipo que me parece importante destacar é a Apropriação Criativa: quando a escola recria a proposta em função das suas necessidades. Então a proposta é assumida pela escola. Os atores envolvidos controlam completamente o processo de inovação.

\section{II - A SEGUNDA PERGUNTA REFERE-SE AOS FATORES QUE CONTRIBUEM NOS RESULTADOS}

1 - Dos antecedentes surge uma série de fatores referentes aos docentes (coordenadores, diretores) associados à experiência de trabalho, expectativas em relaçãs aos seus alunos, etc. Quero destacar o ponto relacionado ao trabalho com os alunos que apresentam maiores dificuldades; assumir a heterogeneidade em termos dos tempos diferenciais e ritmos com os quais as crianças aprendem é um aspecto central para obter melhores rendimentos. É importante destacar que aqueles professores que assumem essa diversidade dos alunos alcançam melhores resultados que aqueles que transferem as crianças com dificuldades para outros especialistas, perdendo a responsabilidade sobre o processo educacional de todas as crianças na sala de aula.

2-Parece-me que falta uma análise do processo educativo. Isso 
significa recolher informações em relação ao impacto dos materiais educativos, tempo de instrução, metodologia, se usam os materiais pedagógicos e livros de textos nas atividades de aula, e como entram as "práticas tradicionais" nesta inovação pedagógica.

3- $\mathrm{O}$ estudo mostra uma série de inovações, aumento de horas, Jornada Única, Ciclo Básico, Escolas-Padrâo, doação de materiais. Cada uma dessas inovações á somativa. Em todas há mais tempo de permanência na escola; em todas há maior adoção de livros. Então, como separamos cada um desses fatores que se repetem nestes diferentes estratos considerados na amostra? Qual desses fatores passa a ser mais importante? O que têm as Escolas-Padrão que as restantes não têm, em termos de inovações ou insumos que se adicionam ao processo educativo? Do modo como está não fica claro o que é diferente e o que produz o impacto. Ou são todas estas variáveis juntas que vão se potencializando e produzem uma sinergia entre elas?

4 - Associado ao impacto dos fatores, seria conveniente ter um estudo de custo-efetividade, que não aparece no documento. Mas entendo que é produto de outra investigação. Os insumos têm custos distintos e na hora de tomar decisões, temos que tomá-las nas áreas da pedagogia e do financiamento.

\section{III - A tercerra PERgunta REFERE-SE Às MODIFICAÇŐEs dos ÍNDICES DA REPETÊNCIA E EVASÃO NA ESCOLA}

1 - Sobre este ponto, é preocupante o penúltimo parágrafo do documento que fala sobre a expulsão dos alunos nas escolas com melhor rendimento. A melhoria nas escolas não deve gerar sob hipotese alguma segregação. Quer dizer, devemos cuidar que as boas escolas sejam para todas as crianças, e evitar que os alunos com maiores dificuldades se concentrem em escolas com menores rendimentos. No caso chileno este é um tema crucial. A medição provoca, com o tempo, um processo de seletividade nas escolas que querem mostrar melhores rendimentos. Para isto, tendem a expulsar ou autorizar os alunos.

A melhoria da qualidade das escolas deve estar acompanhada de um processo que gere igualdade de oportunidades para todos, e não exclusões. Este ponto parece-me central na hora de ver o impacto.

2-Sobre o tema rendimento dos alunos e o comportamento desses grupos parece-me importante estabelecer medições por grupos de alunos.

Isto é, trabalhar com decimais ou porcentagens de maior ou menor rendimento e começar a ver qual é o comportamento interno em cada um dos estratos analisados. Deste modo, podemos mostrar o impacto na 
população mais vunerável - aquelas mais expostas à repetência e evasão comparada á população menos vunerável. A melhoria de qualidade deve superar as desigualdades educacionais. Creio que este é um elemento importante.

Gostaria de destacar o impacto das variáveis intra-escolares que aparecem no estudo. Isto significa que se existe mesmo desigualdade educacional - cuja origem está $\mathrm{cm}$ fatores endógeneos à escola e que tem a ver como as crianças chegam e penetram no sistema escolar -, há uma proporção de variáveis sobre as quais podemos interferir e gerar campos de ação para que as escolas atinjam melhorias na aprendizagem. O estudo mostra uma série de variáveis que são intra-escolares, em que podemos tomar decisões e intervir diretamente como pessoas do campo educacional.

Finalmente, gostaria de estabelecer a necessidade de incorporar neste Estudo de Avaliação de Impacto um sistema de disseminação de resultados, e como estes resultados chegam e são trabalhados em cada uma das escolas e em cada umas das salas de aula. Creio que o tema dos grupos não diz respeito apenas às escolas, mas também às crianças nas salas de aula. 
